\title{
Oxidative depolymerization of lignin using a novel Polyoxometalate-protic ionic liquid system.
}

Gilbert F. De Gregorio, ${ }^{a}$ Raquel Prado,,${ }^{a}$ Charles Vriamont, ${ }^{b}$ Xavier Erdocia, ${ }^{c}$ Jalel Labidi, ${ }^{c}$ Jason P. Hallett ${ }^{\mathrm{b}}$ and Tom Welton ${ }^{\mathrm{a}}$

${ }^{a}$ Department of Chemistry, Imperial College London, Exhibition Road, London, UK SW7 2AZ

${ }^{b}$ Department of Chemical Engineering, Imperial College London, Exhibition Road, London, UK SW7 $2 A Z$

${ }^{b}$ Department of Chemical Engineering and Environment University of Basque Country, Plaza Europa

1, Donostia-San Sebastian, Spain, 20018

Supporting Information (3 pages)

Table of Contents

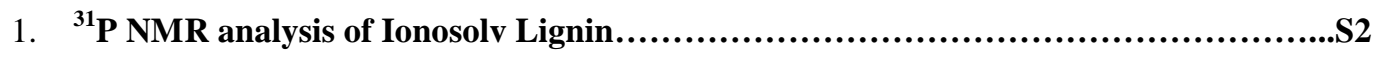

2. Preparation of Pentaimidazolium-10-molybdo-2-vanadophosphate.....................S2

3. Oxidative depolymerization of Ionosolv lignin using hydrogen peroxide as an

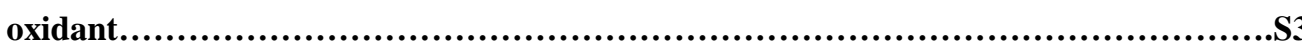

4. Oxidative depolymerization of Ionosolv lignin using molecular oxygen as an

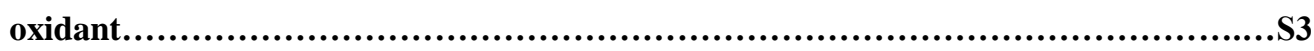

5. GC-MS analysis of lignin post oxidative depolymerization..........................S3 


\section{1. ${ }^{31} \mathrm{P}$ NMR analysis of Ionosolv Lignin}

Quantitative ${ }^{31} \mathrm{P}$ NMR spectra of all lignin preparations were obtained using published procedures. ${ }^{1,2}$ The solvent was prepared using anhydrous pyridine and deuterated chloroform solvent solution (1.6:1, $\mathrm{v} / \mathrm{v})$. A second mixture solution was prepared containing $3.6 \mathrm{mg}$ of chromium (III) acetylacetonate solution $\left(5.6 \mathrm{mg} / \mathrm{mL}\right.$ in the pyridine $/ \mathrm{CDCl}_{3}$ solution) as a relaxation reagent. Approximately $10 \mathrm{mg}$ of previously dried Ionosolv lignin was accurately weighed into a $2 \mathrm{~mL}$ glass HPLC vial. An aliquot of $100 \mathrm{~mL}$ of anhydrous pyridine and chloroform solution was added under stirring. This was followed by the addition of $50 \mathrm{~mL}$ of cyclohexanol $(20.5 \mathrm{mg} / \mathrm{mL}$ in pyridine/CDCl 3 solution), as an internal standard and $50 \mathrm{~mL}$ of the chromium (III) acetylacetonate solution. Finally, $50 \mathrm{~mL}$ of the phosphitylating reagent (TMDP) was introduced and the sealed solution vortex mixed intensely for around 5 minutes or until completely dissolved. Then the samples were transferred into Shigemi NMR tubes. All the above solutions were protected under nitrogen. The NMR experiments were carried out at $209 \mathrm{~K}$ on a Bruker Avance $500 \mathrm{MHz}$ NMR spectrometer. A relaxation delay of $25 \mathrm{~s}$ was used between $30^{\circ}$ pulses, and the number of scans was 127. An inverse gated decoupling pulse sequence was used to obtain quantitative spectra. The acquisitions were performed at room temperature. Chemical shifts were calibrated relative to the internal standard, i.e. the cyclohexanol peak signal centered at $144.2 \mathrm{ppm}$. Quantitative estimates of the various hydroxyl containing functional groups were made by calibrating to the integration region of the internal standard signal (cyclohexanol) and normalizing by the weight of the lignin sample to obtain a value in $\mathrm{mmol} \mathrm{OH/g} \mathrm{lignin}$.

\section{Preparation of Pentaimidazolium-10-Molybdo-2-vanadophosphate ${ }^{3}$}

Sodium metavanadate, $12.2 \mathrm{~g}$, was dissolved by boiling in $50 \mathrm{~mL}$ of distilled water then mixed with $3.55 \mathrm{~g}$ of $\mathrm{Na}_{2} \mathrm{HPO}_{4}$ in $50 \mathrm{~mL}$ of water. After the solution was cooled, $2.5 \mathrm{~mL}$ of concentrated sulfuric acid was added and the solution developed a red color. An addition of $60.5 \mathrm{~g}$ of $\mathrm{Na}_{2} \mathrm{MoO}_{4} \cdot 2 \mathrm{H}_{2} \mathrm{O}$ dissolved in $100 \mathrm{~mL}$ of water was then made. While the solution was vigorously stirred, $42.5 \mathrm{~mL}$ of concentrated sulfuric acid was added slowly, and the hot solution was allowed to cool to room temperature. The 10-molybdo-2-vanadophosphoric acid was then extracted with $250 \mathrm{~mL}$ of diethyl ether. Air was passed through the heteropolyetherate (bottom layer) to free it of ether. The aqueous solution containing the POM was cooled in an ice bath. An excess of 1-butylimidazolium was then added to the aqueous phase to precipitate out an orange solid. The solid formed were filtered, washed with water and air-dried affording a bright orange solid $(65.8 \mathrm{~g})$.

\section{Oxidative depolymerization of Ionosolv lignin using hydrogen peroxide as an oxidant}

The IL ( $1 \mathrm{~g}$ ) was placed in a $10 \mathrm{~mL}$ pear-shaped flask loaded with a flea magnet and a subaseal. The appropriate amount of catalyst was then loaded and the $\mathrm{IL}$ - catalyst mixture was left to stir at $100{ }^{\circ} \mathrm{C}$ for one hour until complete dissolution of the catalyst was observed. The solution was then left to cool to room temperature. Hydrogen peroxide was then added $\left(166 \mu \mathrm{L}, 37\right.$ wt $\%$ in $\left.\mathrm{H}_{2} \mathrm{O}\right)$ and was left to stir for ten minutes. Lignin was finally added $(30 \mathrm{mg})$ to the pear-shaped flask. The lignin and IL-catalyst 
mixture was then placed in an oil bath, capped with a suba-seal with a needle outlet. The reaction was left to stir for the allotted time under stirring and then left to cool to room temperature. Distilled water was then added to the flask $(3 \mathrm{~mL})$ in order to the precipitate out the unreacted lignin and POM catalyst. The content of the flask was then poured into a pre-weighed falcon tube and a further $2 \mathrm{~mL}$ of water was used to rinse out the flask. The tube was then centrifuged at $4000 \mathrm{rpm}$ for 10 minutes. The aqueous layer was decanted from the solid and kept aside. A further $5 \mathrm{~mL}$ of water was added to the falcon tube containing the solids and the mixture was centrifuged once again. The supernatant was decanted and disposed of whilst the solids in the tube were dried in an oven at $50{ }^{\circ} \mathrm{C}$ overnight to remove the remaining water. The lignin content was then weighed to determine the amount of reacted lignin. The depolymerized products in the aqueous layer were then extracted through washing with ethyl acetate $(3 \times 2 \mathrm{~mL})$. The organic washings were then removed under reduced pressure, weighed and then analyzed by GC-MS.

\section{Oxidative depolymerization of Ionosolv lignin using molecular oxygen as an oxidant}

Oxidative depolymerization of Ionosolv lignin using molecular oxygen as an oxidant followed the same protocol as above with the addition of oxygen replacing hydrogen peroxide. Once the lignin and POM-PILs mixture was placed in an oil bath, an oxygen inlet was inserted through the suba-seal and into the flask. The oxygen flow rate was regulated to ensure saturation of the mixture.

\section{GC-MS analysis of lignin post oxidative depolymerization}

Gas chromatography-mass spectra characterization was carried out via GC (7890A)-MS (5975C inert MSD with Triple-Axis Detector) Agilent equipped with a capillary column HP-5MS ((5\%- Phenyl)methylpolysiloxane, $60 \mathrm{~m} \times 0.32 \mathrm{~mm}$ ). The temperature program started at $50{ }^{\circ} \mathrm{C}$ then was raised to $120{ }^{\circ} \mathrm{C}$ at $10{ }^{\circ} \mathrm{C} \mathrm{min}{ }^{-1}$, held for 8 minutes, raised to $280{ }^{\circ} \mathrm{C}$ at $10{ }^{\circ} \mathrm{C} \mathrm{min}{ }^{-1}$, held for 5 minutes, raised to

$300{ }^{\circ} \mathrm{C}$ at $10{ }^{\circ} \mathrm{C} \min ^{-1}$ and held for 2 minutes. Helium was used as the carrier gas. Calibration curves were established using pure compounds (Sigma-Aldrich)- phenol, o-cresol, m-cresol, p-cresol, guaiacol, catechol, 4-methylcatechol, syringol, acetovanillone, syringaldehyde, acetosyringone and 4hydroxy-3-methoxyphenylacetone.

\section{References:}

1. Pu, Y.; Cao, S.; Ragauskas, A. J. Energy Environ. Sci. 201, 4, 3154.

2. Crestini, C.; Argyropoulos, D. S. J. Agric. Food Chem. 1997, 45, 1212-1219.

3. Tsigdinos, G; Hallada, C. Inorg. Chem. 1968, 7, 437-441. 